\title{
“AMOR DE ARTUR”, DE MÉNDÉZ FERRÍN: UMA RELEITURA DO MITO SOB A PERSPECTIVA GALEGA
}

Aline de Almeida Moura

Wenceslau Teodoro Coral

\begin{abstract}
A História é o mais perigoso produto da química de intelecto. Suas propriedades são bem conhecidas. Produz sonhos, intoxica povos inteiros, lhes oferece falsas memórias, estimula seus reflexos, mantém suas feridas abertas, os atormenta das horas de tranqüilidade, os conduz a desilusões de grandeza ou perseguição, e torna as nações amargas, arrogantes, insuportáveis e vãs. (Paul Valéry)
\end{abstract}

\section{Introdução}

Mnemósine (Memória) gera nove Musas, tidas com virgens ligadas à poesia e à música, além de inspiradoras dos poetas na tradição grega. É através do canto das Musas que o homem pode transcender suas fronteiras geográficas e temporais e observar fatos, figuras e superar bloqueios impostos pela realidade empírica. Assim, a Memória, ao fazer surgir as inspiradoras das artes, concede grande poder ao homem: impor-se através do tempo e do espaço, fazer-se presente. Dessa forma, a memória tem grande relevância na construção e na união da identidade de uma sociedade na medida em que une os indivíduos em torno de uma visão de mundo e de história.

O presente artigo pretende abordar como a apropriação do mito arturiano feito por Mendéz Ferrín contribui para o fortalecimento da memória coletiva galega como nação, em um primeiro momento, utilizando noções como identidade e memória. Num segundo momento, levando em conta que "o passado é apreendido no presente e responde, portanto aos seus interesses, o que não é só inevitável, como legítimo" (LE GOFF: 1996, p.51), procurar-se-á entender a forma como esse mito foi apropriado por Ferrín, principalmente em relação à busca que há na construção narrativa. Para tal estudo, analisar-se-á o conto "Amor de Artur", texto presente em livro homônimo lançado pela primeira vez em 1982. Escolheu-se esse texto como base para o estudo a que se propõe à medida que, como afirma Flavio García, nesse texto o autor "reconstrói o mito para que a ação do tempo não corroa sua memória. Isso vem ratificar o jogo de releituras presente na narrativa ferriniana" (GARCÍA: 2004, p. 66), relembrando, a 
partir desse texto contemporâneo, o passado de glória desse povo. Desta forma, Galícia, uma das dezessete comunidades espanholas que enfrentou inúmeras dificuldades na construção de sua autonomia, consegue se manter unida, tendo como grande auxílio para essa manutenção a Arte e seus mitos, aspectos muito relevantes durante vários períodos da história galega.

Para conseguir alcançar o objetivo do texto, primeiramente será apresentado a narrativa analisada e sua ligação com o mito arturiano. Em seguida, serão tratadas as questões do mito e da memória, percebendo como esses aspectos tem relevância para o entendimento da narrativa. Também será feita uma breve análise sobre a questão do Maravilhoso, enquanto gênero importante para a narrativa. Finalizar-se-á com a análise da narrativa propriamente dita, já com a base anteriormente construída pelos apontamentos teóricos realizados.

\section{“Amor de Artur”: uma releitura}

O conto narra a história do rei Artur, que descobre "pola boca mesturadora de Galván, que Guenebra lle era infidel con Lanzarote" (MÉNDEZ FERRÍN: 1993, s/p). Em um só momento, ele é traído pelos dois seres que mais amava: a sua esposa e o seu fiel cavalheiro. A partir disso, parte em direção em Genebra, no intuito de restabelecer a sua relação com ela, perdoando-a por acreditar que ela estaria arrependida da traição cometida. Contudo, ela se recusa a retornar para junto de Artur, o que o deixa transtornado e humilhado: "Nas mentes de Guenebra componse un non rúnico, unha negativa pétrea, un rexeito granado en seixos rotos e ferintes” (MÉNDEZ FERRÍN: 1993, s/p). Nesse momento, ele parte em busca de respostas para entender porque sua amada não quis retornar aos seus braços, acreditando que só Merlin conforta-lo.

Nessa busca pelo mago, rei Artur se cansa e, ao tentar descansar, tem um sono inquieto, no qual sonha com Francastel e se encontra com Merlin que o aconselha a procurar o encantador Roebek, de Tagen Ata. Durante a viagem para o encontro com Roebek:

Rei Artur viu voar un bando de ciños sobre o Lago Espadanedo, e considerouno unha indicación de que as sombras desexaban que detivese alí mesmo a súa viaxe. Mandou fincar as tendas e separouse da súa xente. Camiñou senlleiro polas carpazas, suspirando a miude. (MÉNDEZ FERRÍN: 1993, s/p) 
Ao parar, outro evento insólito acontece: rei Artur sente a presença de inumeráveis pessoas e empunha sua espada Excalibur. Contudo, reconhece Dagda, "irlandés dos profundos da terra: o poderoso deus perdido, o grande campeón do comer e do amar" (MÉNDEZ FERRÍN: 1993, s/p). Ele lhe dá três avisos: "que se vele de Galván, protexido de Lug, e que non escoite os seus ditos pois el móvese só por envexas de Lanzarote. A dúas: que siga ao pé da letra os consellos de Roebek de Tagen Ata. A tres: que as aves tornan sempre ao puño do seu amo". (MÉNDEZ FERRÍN: 1993, s/p)

Enquanto aguarda pelo sinal de Roebek, em Tagen Ata, refugiado em uma pousada, rei Artur se depará com um fato inusitado: um cavalheiro ao receber seu prato, chora compulsivamente e foge. Ao encontrar com Roebek, Autur relata a situação do cavalheiro e o sábio conta a história:

O cabaleiro que viches na pousada vivía moi feliz na súa terra. Con el tiña un seu fillo pequeno, a quem amaba sobre todas as cousas. O cabaleiro disfoitaba moito coa cetrería e tiña unha aguia ensinada que era a máis veloz e valente ave de presa que puidera ser no mundo. Un día, a aguia arrebatoulle ao cabaleiro e seu fillo e saíu voando, con el nas poutas, cara as montañas. O cabaleiro chorou moito a perda do ser que máis quería e, un día, paseando ao azar cun seu besteiro, viu como a que fora súa aguia daba caza a un coello. Desexoso de se vingar de quen lle roubara o fillo, ordenou ao basteiro que matase ao coello a fin de deixar a aguia sen a súa presa. Así o fixo o besteiro e a aguia fuxiu velozmente ás alturas. Colleu o cabaleiro o coello e dirixiuse á festa dde Conarán. Foi aí cando te viches como entregaba o coello ao pousadeiro e como lle pedía que o adoviase. Cando este llo apresentou cociñado, o cabaleiro ollou pra el e viu que o coello tiña os ollos do seu fillo, o roubado pola aguia. Daquela chorou amargamente. (MÉNDEZ FERRÍN: 1993, s/p)

Roebek então diz que a história é na verdade um enigma e que deverá procurar Liliana, esposa secreta de Lancelote, para resolver seu problema, deitando-se com ela. Ao se encontrar com ela, o rei fica inebriado pela paixão:

Cando abre os ollos, os ollos de Liliana descóbrenlle un puzo de amor inmenso no que bebe Artur augas mestas de sabedoría. Porque os ollos de Liliana falan todo. Os ollos de Liliana son os ollos de Guenebra e Liliana era coma Guenebra porque ambas amaban a Lanzarote e Lanzarote amaba a ambas e a través de Lanzarote circulaban linfas de identidade escura e rutilante. Todos amaban a Artur no seu deliquio. E Rei Artur choraba, como o cabaleiro da pousada ao ollar no coello os ollos do seu 
fillo perdido. Porque o coello era Liliana; o fillo roubado, Guenebra; a aguia ladra, Lanzarote; e Rei Artur, o cabaleiro do enigma de Roebek de Tagen Ata. Daquela aloumiñou en veludos a orella do Rei a voz de Liliana, que molemente cantaba sen abrir a boca. A penas coa ollada, ía pondo verbas de dozura incompleta, como rosáceas nubes de cotón nos crepúsculos de Cornoalla. Sen deixar de enguedellar os dedos na barba de Artur, prorrumpía en tropos, estrofes, estramonios amargues nos que o gancho do refrán que volta sempre pon unha longura infinita no retornar eterno da cantiga secreta. (MÉNDEZ FERRÍN: 1993, s/p)

Rei Artur, enfim, alcança seu Graal interior e entende o significado do enigma do homem. Percebe-se que o conto de Mendez Ferrin retoma a clássica história do círculo arturiano, em que o rei Artur é traído pela mulher e pelo melhor amigo ao mesmo tempo. É interessante ressaltar que a releitura ferriniana não substitui as outras leituras, além de não estabelecer significados definitivos para o texto. De fato, coexiste e argumenta com as outras leituras ao propor uma nova visão dos "fatos".

Ferrin convida o leitor a ter um outro olhar sobre o mito arturiano, mas trazendo uma perspectiva contemporânea. Uma releitura que traz aspectos que iluminam as buscas de seu tempo. De acordo com Guedes,

A ficção pós-moderna também investiga a construção e a representação da identidade, da subjetividade e da sexualidade; reconhece a diferença e incorpora em seus textos a diversidade multicultural e étnica do mundo ocidental; elimina a antiga distinção entre a cultura erudita e popular em suas diversas manifestações; examina a relação entre história e ficção, enfatizando sua natureza de discursos; chama a atenção do leitor para a natureza de discursos (...); apropria-se das e reescreve as chamadas "grande narrativas" ou "narrativas-mestras" da literatura ocidental, expondo seus viéses e estereótipos, e desafiando as ideologias e relações de poder inseridas nestas narrativas. (GUEDES: 2001, p. 136-137)

Assim, afirma-se que a escolha pela retomada da história de Artur não é gratuita, principalmente por se tratar de um autor galego, mesmo sendo esse mito tão recorrente em diversas formas na literatura ocidental. Além disso, a forma pela qual a história é narrada por Ferrín demonstra e sua forma de encarar os preconceitos e estruturas existentes na história. Ao dar uma nova roupagem, fica evidente que ele tenta aproximar esse mito de uma visão mais contemporânea. 
A questão da memória

A memória coletiva corresponde à parte "mítica, deformada, anacrônica, mas constitui o vivido desta relação nunca acabada entre o presente e o passado" (LE GOFF: 1996, p. 29). O mito resgatado através da narrativa tem como objetivo retornar à memória de um tempo de sabedoria e de glória. Como afirma García, mesmo que alguns autores tentem negar:

Galiza é 'o país da brétema', envolto num nevoeiro que evoca Ávalon. A viagem no tempo pela cultura celta é, na verdade, uma viagem pelas origens mítico-históricas da Galiza. (...) Trata-se, na verdade, de uma viagem pela memória em direção às bases calaicas, à configuração étnica do bravo povo ibérico que enfrentou os romanos e não se deixou escravizar. (GARCÍA: s/d, p. 2)

No caso de "Amor de Artur", a função do mito "consiste em revelar os modelos exemplares de todos os ritos e atividades humanas significativas” (ELIADE: 1963, p. 13), assim como a sabedoria que é buscada por Artur, a fim de entender sua condição.

Segundo Pollak, "a referência ao passado serve para manter a coesão dos grupos" (POLLAK: 1989, p. 9), incentivando a defesa de um povo, de um território. O passado se torna o lugar onde se procura raiz e identidade (Cf.: LE GOFF: 1996, p. 224). No conto, Artur também relembra o passado de amor e regozijo com Genebra e, por isso, pretende restabelecer a sua vida com ela tal como era anteriormente:

Ela fora a benamada, a única, a gavota do mencer chuvento, a pel cegadora de neve ardorosa, a seguranza pétrea dos estados, o azafrán dos xantares de cerimonia, cendal de Persia na fronte queimada dos estíos, noites de brama dos veados beira do pabillón de caza a amatar os outros brados de amor de bronce señorial entre doseis e peles de londra, e o corpo nu dela a renovarse no leito co movemento incesante e diverso das fervenzas (...) Rei Artur só anceia, derrubado na tarde de chumbo, recuperar, recuperar a pel de Guenebra, voltala a si, descubrir de novo o quentor de horas pasadas e líquidos grumentos de desexos obtidos ensoños acoplados nos seráns da gloria e dos floridos banquetes, que Guenebra, garza, grou, galana, volte, e que Lanzarote endexamais torne de Armórica se non é pra recibir o deshonor de mans de Rei Artur. (MÉNDEZ FERRÍN: 1993, s/p)

A questão da identidade também é de extrema relevância. Segundo Stuart Hall: 
As culturas nacionais, ao produzir sentido sobre a "nação", sentido com os quais podemos nos identificar, constroem identidades. Esses sentidos estão contidos nas estórias que são contadas sobre as nações, memória que conectam seu presente com seu passado e imagem que dela sã construídas. (HALL: 2003, p. 51)

Ou seja, embora na contemporaneidade haja um afrouxamento das culturas nacionais e locais (Cf.: HALL, 2003), para o povo galego essa busca permanece á medida que sofreram diversos ataques a sua identidade enquanto nação ao longo de sua história.

Etimologicamente, identidade deriva da raiz idem, que implica igualdade e continuidade, ou seja, as pessoas constroem a sua identidade pessoal a partir da cultura e o nacionalismo exige que o grupo político e o grupo étnico sejam congruentes, impondo de certa forma uma união entre o Estado nacional e a cultura nacional. Segundo Antonio Candido, "a literatura foi considerada parcela dum esforço construtivo mais amplo, denotando o intuito de contribuir para a grandeza da nação" (Cf.: CANDIDO: 1997, p. 12), fazendo com que a escolha do tema seja fundamental para a constituição dessa identidade.

É com a releitura da matéria da Bretanha que Ferrín reafirma a identidade de seu povo. Mesmo na construção de seu texto, ressalta-se que Tagen Ata é o termo utilizado para designar a própria Galicia nas obras de Méndez Ferrín e é lá que Artur vai achar a resposta para a traição que de Genebra e Lancelote.

\section{O mito em “Amor de Artur”}

O mito - matéria-prima dessa narrativa - constitui uma estrutura permanente que se relaciona, simultaneamente, com o passado, o presente e o futuro, sendo que a Galícia, por se sentir originada pelos celtas, incorpora os seus mitos para relembrar um tempo no qual o galego não passava por nenhuma fase de repressão, conectando o presente com esse passado de prestígio:

Valendo-se do mito celta - a tradição vê os galegos como descendentes diretos da civilização celta na Península, herdeiros da Deusa-Nai - Méndez Ferrín tematiza a problemática interna da Galícia. (...) Isso está na memória histórica. Com esse recurso, Méndez Ferrín iluminou traços despercebidos da identidade galega, procurando explicar sua existência atual. (GARCÍA, s/d, tendências da narrativa curta) 
Assim, Ferrín reconstrói o mito e une ao universo diegético elementos do mundo Maravilhoso como recurso de reconstrução da memória galega em relação ao passado celta. Assim, em "Amor de Artur", há uma re-visitação da lenda arturiana, tomando como personagens principais Artur, Lancelote, Genebra, Merlim, entre outros. Ele incorpora aspectos novos como uma visão platônica do mito andrógino ao fazer "com que Lancelote e Artur representem o andrógino masculino; Genebra e Liliana, o andrógino feminino e os casais Liliana e Lancelote, Artur e Genebra, o andrógino dual”, como apresenta a leitura feita por Sieczkowski (2004, p. 75). Ressalta-se que o mito andrógino se refere, de acordo com a explicação mitológica, há um tempo em que não havia homens e mulheres, mas seres superiores aos humanos, os andróginos, dotados de quatro braços, quatro pernas, uma cabeça com duas faces opostas e dois sexos. Providos de força e agilidade sobre-humanas, tornaram-se orgulhosos e, inconseqüentes, empreenderam uma escalada até o céu. Zeus não gostou da ousadia e, zangado, dividiu cada andrógino em dois. Desde então, a humanidade ficou dividida em duas partes que se procuram para voltar ao original.

O paganismo bárbaro, no caso, o celta, também chamado de "matéria da Bretanha", se mostra como fonte inestimável para a construção do imaginário galego, se tornando "um grande reservatório de maravilhoso que irriga os grandes ciclos romanescos e legendários" (LE GOFF: 2002, p. 110), e como os galegos são tidos de origem celta, era esperado que se retomasse este universo. Além disso, no período medieval, mais especificamente no século XII, a língua galega se torna a língua lírica por excelência, eram muitos os poetas de fora de Galícia que adotavam o galego como língua poética, tornando-a referência nesse período histórico, o que possibilita um retorno a esse momento.

Ao retomar estes mitos de origem medieval, é inevitável a incorporação de eventos insólitos na narrativa, caracterizado "pela raridade e pelo espanto que suscita, em geral admirativo. Ele afeta primariamente o olhar e implica qualquer coisa de visual” (LE GOFF: 2002, p. 106-107). Pois é através de um evento insólito que Artur é colocado diante do enigma que resolverá sua inquietação. A narrativa de caráter oral transmitida pelo caçador que teve o filho levado pela águia é o que introduz Artur no caminho da sabedoria, ou seja, pela experiência do outro é que se tem contato com esta sabedoria, a experiência passada por um homem que sente uma dor como a de Artur. 
Aqui é resgatado um valor que Walter Benjamin alerta estar desaparecendo: "a faculdade de intercambiar experiências" (BENJAMIN: 1994, p. 198), dentro o qual se resgata também o intercâmbio das experiências contidas nas narrativas sobre e acerca dos mitos presentes no conto.

\section{O maravilhoso medieval na contemporaneidade}

O maravilhoso é um objeto cultural e psicológico que possuiu diversas fases ao decorrer da Idade Média. Durante a Alta Idade Média, período que corresponde aos séculos V-X, percebe-se uma luta contra o paganismo e as superstições populares, havendo uma incorporação do milagre cristão, pelos santos e novos heróis. Numa segunda fase que incorpora o século XI, mas principalmente o XI e XII, há "um vivo reflorescimento do maravilhoso, em razão de certo relaxamento exercido pelo controle da Igreja, que se consagra essencialmente à luta contra os hereges" (LE GOFF: 2002, p. 107). Entretanto, na passagem do século XII ao XIII inicia-se a crise do sistema medieval extraordinário, "discernindo entre o miraculoso de origem divina e o mágico de natureza diabólica" (LE GOFF: 2002, p. 107). Finalmente no século XIV e XV, há uma estetização do maravilhoso ao torná-lo mais literário que religioso.

Este universo, objeto de estudo dos historiadores medievalistas, é incorporado nos estudos literários através do gênero Maravilhoso ao estruturar suas narrativas em eventos insólitos de forma natural, rompendo com a atual perspectiva do que é plausível ocorrer. Esse gênero participa da categoria do insólito, sendo Méndez Ferrín um importante veículo de conhecimento desse universo insólito já que o re-elabora e o resignifica.

O maravilhoso joga com as fronteiras entre o natural e o sobrenatural, mostrando a relação do deífico com o homem. O maravilhoso medieval se caracteriza pela raridade, pelo esponto, pela admiração.

Em “Amor de Arthur” há uma forte ligação com a tradição galega resultante de um desejo de que a identidade galega venha de valores eternos, em que não há espaço nem para o contemporâneo. Assim, a literatura devia se basear na tradição anterior.

A retomada dessa tradição, além de fazer parte de uma reconstrução da memória coletiva, é característica dos textos pós-modernos, fase do modernismo no qual se percebe um questionamento dos paradigmas burgueses (Cf.: HUTCHEON: 1991). Um dos aspectos desse período na literatura é o pastiche, que se refere a uma obra que é 
derivada de trabalhos pré-existentes. Evidencia a manipulação da linguagem, contrapondo estilos, tratamento da temática, foco, etc. Torna-se relevante a medida que se liga à procura pela identidade pela apropriação deliberada do textos canônicos. Além disso, permite visualizar o mundo e a cultura como variados fragmentos permanentemente reutilizáveis. Aspecto bastante claro no texto comentado - "Amor de Artur", já que se retoma o passado galego por intermédio da memória coletiva, sem preocupação em analisar fontes entre outros. Esta é uma leitura sob um viés da contemporaneidade, onde os temas clássicos são escritos com outra perspectiva, na qual todas as coisas se ligam. Dessa forma, vê-se em “Amor de Artur”, a busca pelo sentido de sua vida com Genebra, nessa busca, se perde e se encontra, ele se esvazia de seu sentido e o acha nos braços de outra mulher, vivendo em lugar que não tem referência na realidade referencial, Avalon.

Além disso, o maravilhoso possui função compensatória, ao criar um universo de permissividade e abundancia num mundo empírico de penúria, repressão e violência. Ou seja, amplia-se a realidade a fim de consolar as frustrações e abris janelas para uma nova perspectiva menos maniqueísta, em que há realização e não evasão.

\section{A busca na narrativa}

Além disso, outra característica relevante em relação ao interesse por esse passado mítico é a própria trama de "Amor de Artur”, já que Artur também se lança em uma busca pela restauração de uma ordem:

Xosé Luís Méndez Ferrín recorre à mitologia celta para tentar explicar o ser galego de hoje, para dar conta dos processos internos de construção da galeguidade, seus desejos, suas lutas, seus processos internos de constituição nacional. Dialogando diferentes textos, em sentido lato, diferentes momentos, Méndez Ferrín dá voz a uma nova e outra história da Galiza, que lê o presente sem abrir do passado, que valoriza a tradição oral, perpetuada ao longo dos tempos no calor do fogar das cozinhas. (GARCÍA: s/d, p. 2)

A busca que observamos em "Amor de Artur”, de Mendez Ferrín, é semelhante a busca do Graal. Ora, Artur, o grande rei, é traído pela rainha, Genebra, que se recusa a vê-lo novamente e a retornar ao seu lar junto de Artur. Logo, ele sai em busca de uma resposta para o que aconteceu, Artur não sabe por onde começar, pois o amor é como o Graal, ele é efêmero, é difícil defini-lo. Embora todos saibam o que é, quando a 
pergunta é feita a resposta se esvai em brumas como os caminhos para Avalon. O caminho para o Graal e para as angústias de Artur serão apenas conseguidas se ele alcançar a sabedoria necessária, sendo essa uma das razões da viagem do rei.

Com esse tema o conto "Amor de Artur", através do resgate da memória de um passado mitológico da cultura celta faz de Artur, aquele que busca respostas para si, o sujeito que só se redime diante da identificação com outra história de perda e sofrimento, como é visto mais adiante no conto com a narração da história do caçador que perde o filho para a águia.

Então, Artur conta para Roebek: "- Hai uns instantes - dixo Artur como falando pra si mesmo - vin na praza un fidalgo que choraba á vista dun coello. Non sei por que non se me vai das mentes. Estou a pensar que ese episodio ten algo que ver coa razóne causa das miñas desditas" (FERRÍN, 1991:28). E o mago conta para o rei sobre o porque de tal cena, dizendo: "- Non te enganas - respondeu Roebek de Tagen Ata como se falase na boca dunha tinalla -, pois a historia do cabaleiro é a cifra da túa propria" (FERRÍN: 1993, p. 28). Então começa a narrar a desventura do caçador.

Assim, “Amor de Artur” seria uma releitura do mito arturiano adaptado a visão do momento galego, pois em território galego existe uma luta e um esforço atualmente para representar e reafirmar a memória e as raízes desse povo. O desespero de Artur, na narrativa ferriniana, pela busca de um sentido, sentido esse paralelo ao graal, seria a mesma busca do povo galego pela sua identidade, por algo com o qual se identifiquem.

Voltando ao início do conto, diz o narrador: "Pasea Artur a tenda de alto a baixo. Pensa que só Merlín poderá confortar o seu cor asoballado cunha sentencia carregada de senso e de consolo" (FERRÍN, 1993:17). Dessa forma vemos a busca, repetidas vezes, pela solução do mago, guardião da sabedoria, aquele que têm a resposta para a angústia que se tornou a vida do rei. Mas o druida, Merlin, indica Roebek:

Antes de o Rei falar, Merlín explícalle que destruíra Francastel no pasado pra non se ver obrigado a recibir nel a Artur e non ter que responder, en virtude das leis da hospitalidade bretona, ás preguntas do Rei sobre o por que amores de Guenebra e Lanzarote do Lago.

- Preferín - di Merlín - non dicirche a verdade.

Atristurado, Rei Artur pídelle ao meigo, polo menos, un consello. 
- Dareiche máis ca un consello - dille este -. Direiche que quen te pode guiar non é outro que o encantador Roebek, de Tagen Ata. (FERRÍN: 1993, s/p)

Roebek lhe mostra um enigma descrito na narrativa sobre o caçador, e que esse enigma se resolverá nos braços de Liliana, esposa secreta de Lancelot, do lago. Quando Artur identifica em Liliana, a própria Guenebra:

Mentras lembra, a súa man percorre o lombo de Liliana cuberto de finísimo veludo de ouro, como o de Guenebra. Como o de Guenebra, pensa Artur, e aparta o cabelo escuro, como o de Guenebra, e bica a fronte de Liliana, os labres inchados e quentes de Liliana, como mesmo os de Guenebra após do amor que eles dous soían. (FERRÍN: 1993, s/p)

Ao se encontrar finalmente com Liliana, ele resolve o enigma do caçador que perdera o filho para a águia, ele finalmente entende que a essência dele se encontra diluída dentro das relações entre Lancelot/Liliana, Lancelot/Artur, Lancelot/Guinevere, Artur/Liliana, Artur/Guinevere:

E Artur daquela que chegou á fin da súa pelerinaxe en procura de qué cousa e qué razón: perda nas perdas que ningún rei namorado endexamais tivera. O sorriso terríbel de Merlín colle a face de Roebek no fondal dos ollos pechos. Cando abre os ollos, os ollos de Liliana descóbrenlle un puzo de amor inmenso no que bebe Artur augas mestas de sabedoría. Porque os ollos de Liliana falan todo. Os ollos de Liliana son os ollos de Guenebra e Liliana era coma Guenebra porque ambas amaban a Lanzarote e Lanzarote amaba a ambas e a través de Lanzarote circulaban linfas de identidade escura e rutilante. Todos amaban a Artur no seu deliquio. (FERRÍN, Mendez: 1993, s/p.)

Ele, Artur, finalmente encontrou a sua resposta ao se entregar e deixar se perder nos braços de Liliana.

\section{Considerações finais}

Assim, levando em conta que os indivíduos são formados pela memória individual - construída através das experiências passadas - e da memória coletiva história e mito -, percebe-se que através da narrativa “Amor de Artur", há um resgate da memória coletiva (representada pelo mito arturiano) em uma leitura contemporânea. Segundo Eco, "esse emaranhado de memória individual e memória coletiva prolonga nossa vida, fazendo-a recuar no tempo, e nos parece uma promessa de imortalidade" 
(ECO: 1994, p. 137). A retomada desse mito tem, portanto, uma função ideológica na qual a apropriação do mito de Artur tem por objetivo reafirmar a identidade galega em sua origem celta, fortalecendo um grupo fragmentado por eventos históricos. E mesma, a trama, em que Artur busca incansavelmente por respostas ao abandono de Genebra retrata a realidade galega atualmente, em que há uma busca pela retomada do passado glorioso e da união do povo.

O trecho final da narrativa parece ser direcionado ao povo galego: "Liliana a fada que gardará o seu soño milenario até que os días da ledicia cheguen de novo ás terras do occidente do mundo nas que as pedras e os silencios atribulan os nosos corazóns escravos, os nosos corazóns escravos" (FERRÍN: 1993, p. 35-36). Embora a intenção não seja de forma alguma fazer uma leitura puramente ideológica do conto, obtêm-se durante a sua análise todos os pontos que apontam para uma construção consciente no sentido de representar de forma literária o resgate da memória e da formação de uma identidade galega, na qual os "corazóns escravos" são o povo galego aguardando pelo retorno dos dias de um passado de importância na história.

Em suma, pode-se ver em Méndez Ferrín a utilização de mitos que evocam a memória coletiva galega, retomando aspectos de sua sociedade e unindo o passado ao presente. A própria releitura do mito de Arthur aponta para essa busca por uma afirmação do mundo galego, pela retomada de um passado. Assim, percebe-se a utilização desses mitos como fonte para promover, através da memória de um povo, a construção de sua identidade.

\section{Referências Bibliográficas}

BENJAMIN, Walter. O narrador: considerações sobre a obra de Nikolai Leskov. In: Magia e técnica, arte e política: ensaios sobre literatura e história da cultura. São Paulo: Brasiliense, 1994, p. 197-221.

CANDIDO, Antonio. Formação da literatura brasileira. 2 volume. Belo HorizonteRio de Janeiro: Editora Itatiaia, 1997.

ECO, Umberto. Seis passeios pelos bosques da ficção. São Paulo: Companhia das Letras, 1994.

ELIADE, Mircea. Mito e realidade. São Paulo: Editora Perspectiva, 1972.

GUEDES, Peonia Viana. Gêneros literários e estratégias narrativas pós-modernas na ficção feminista contemporânea inglesa e norte-americana. In: Revista Palavra 7. Rio de Janeiro: PUCRJ, 2001, p. 136-147

MÉNDEZ FERRÍN, Xosé Luís. Amor de Artur. 2 ed. Vigo: Xerais, 1993. 
LE GOFF, Jacques \& SCHMITT, Jean-Claude (dirs). Dicionário temático do Ocidente Medieval. Bauru, SP: EDUSC, 2002. 2 vols.

LE GOFF, Jacques. História e Memória. Campinas: Editora da UNICAMP, 1996.

HALL, Stuart. A identidade cultural na pós-modernidade. Rio de Janeiro: DP\&A, 2003.

HUTCHEON, Linda. A poética do pós-moderno. Rio de Janeiro: Imago, 1991.

MÉNDEZ FERRÍN, Xosé Luís. Amor de Artur. 2 ed. Vigo: Xerais, 1993.

POLLAK, Michael. "Memória, Esquecimento, Silêncio". In: Estudos Históricos. Rio de Janeiro, vol.2, n 3, 1989.

GARCÍA, Flavio. "Philoctetes". In: GARCÍA, Flavio (org.). Ler Ferrín; ler Galiza: estudos literários. Rio de Janeiro: Dialogarts, 2004, p. 64-70.

"Galiza, terra celta: identidade, contos de vella, literatura". In: Sentidos dos lugares. Rio de Janeiro: ABRALIC. Edição em CD Rom. 2005.

SIECZKOWSKI, Luís Flávio. “Amor de Artur”. In: GARCÍA, Flavio (org.). Ler Ferrín; ler Galiza: estudos literários. Rio de Janeiro: Dialogarts, 2004, p. 64-70. 